\title{
PERIOPERATIVE SAFETY DEVICES
}

Ansell offers an innovative line of Sandel perioperative safety devices designed to eliminate the threat of workplace injury before, during and after surgery. The product range, identified by its signature bright orange colour, was developed in close collaboration with healthcare professionals and will help raise

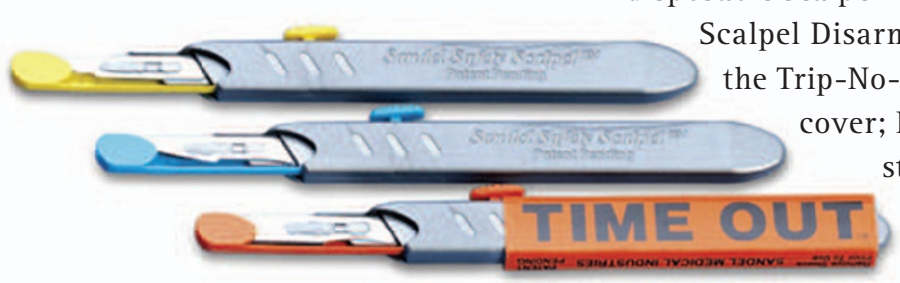

safety standards in line with EC and WHO regulations.

The Sandel range features around 50 products and focuses on three target areas: engineered sharps injury prevention, ergonomic workplace safety and wrongsite surgery prevention. They include the Change-A-Blade disposable scalpel handle; the Scalpel Disarmer blade; stools; and the Sandel Time Out wrongsite surgery prevention products. www.ansell.eu

\section{INCREDIBLY EASY DIGITAL DENTISTRY}

With the Planmeca ProMax 3D and 2D digital panoramic unit, patient positioning is made incredibly easy with the triple laser beam system that shows the correct anatomical positioning. In 3D programs, positioning lasers and joystick are used for fine adjustments. With full view open patient positioning there is direct visual contact without the need for mirrors, ensuring a relaxed patient. ProMax provides side entry for easy access whether the patient is standing or sitting and wheelchairs are easily accommodated. The intuitive graphical user interface offers pre-programmed target sites and exposure values for different image types and targets. Intuitive controls provide efficient workflow; clear commands and graphic icons make the graphical user interface (GUI) very easy to use which allows for the user to focus on positioning and communicating with the patient. When imaging is completed a preview image shows on the main display.

The next big innovation from Plandent is digital impression taking with the latest 3Shape TRIOS intraoral digital scanner. TRIOS intraoral scanner is capable of taking 3,000 2D pictures per second, to create the final 3D digital impression based on real data, easily capturing single implant positions right though to full scans of both upper and lower jaws with full occlusal visualisation.

With TRIOS no-spray there is no need to hold the scanner at a specific distance or angle for focus. The Smart-Touch screen with live 3D visualisation offers intuitive user-functionality with advantages for both the operator and patient - improved accuracy and clinical results, no impression material or mess, reduced need for retakes, fewer chairside adjustments, and less surgery time per procedure.

For further information call Plandent on Freecall 0500500322.

\section{LESS ABRASIVE THAN OTHER TOOTHPASTES}

Laboratory testing has confirmed that whitening toothpaste brand Beverly Hills Formula is less abrasive than other leading brands of both whitening and regular toothpastes.

Any toothpaste with a value over 100 RDA (relative dentine abrasivity) is considered to be abrasive, and can damage teeth and gums. As tooth enamel wears away the dentine becomes more visible and teeth become more yellow, and can also become sensitive to hot and cold temperatures. Beverly Hills Formula Total Breath Whitening toothpaste scored as low as 90 on the RDA table, ensuring your patients are protected against tooth decay while helping restore their teeth to a natural white colour.

Other products within the range also scored exceptionally well with Beverly Hills Formula Perfect White toothpaste scoring 95 and Natural Whitening Expert toothpaste scoring 99, while some leading competitors have levels as high as 138. These latest results support the 2011 studies that found Beverly Hills Formula Total Protection toothpaste scored as low as 93 on the RDA Table. Visit www.beverlyhillsformula.com.

\section{A GENTLE SHAKE TO ACTIVATE}

Virofex cleans and disinfects to the highest levels without the complications associated with alcohol based cleaning products. It's safe and effective on glass and metals; plastics including perspex; chair upholstery; all worktops and even plastic parts on medical devices.

Virofex comes in small cartridges which ensure no staff contact with chemicals, no spills or waste, the correct amount will always be used, and it is easy and quick for the whole team to use.

The Virofex cartridge is simply inserted into the neck of a Virofex bottle, which is filled with $500 \mathrm{ml}$ of tap water. The bottle then needs a gentle shake to activate the disinfectant, which then stays active for up to 12 months.

Virofex is a powerful and thorough disinfectant effective against MRSA,

HIV, Influenza

A, salmonella

typhimurium and clostridium difficile and many other viruses, bacteria and spores.

Visit www.

directory.co.uk.

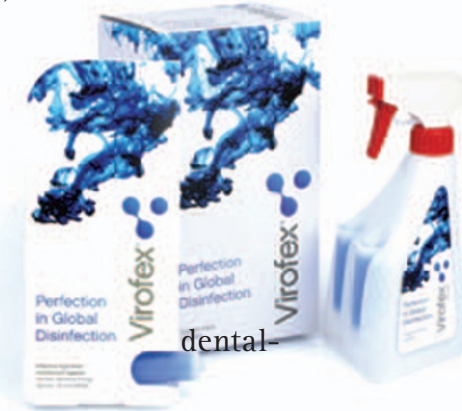

